\title{
REATIVIDADE TUBERCULINICA E RESPOSTA IMUNOLÓGICA CELULAR E HUMORAL "IN VITRO" EM DOENTES COM TUBERCULOSE PULMONAR *
}

\author{
Adele Caterino de Araujo** \\ Augusta Kiyomi Takeda** \\ Cleonice Bego Herrero** \\ Irene Walter de Freitas ** \\ Ivete Kazue Nakandakare** \\ Eloisa Aparecida Guedes *** \\ Roberto Brólio****;
}

\begin{abstract}
ARAUJO, A. C. de et al. Realividade tuberculinica e resposta imunológica celular e humoral "in vitro" em doentes com tuberculose pulmonar. Rev. Saúde públ., S. Paulo, 17:94-111, 1983.
\end{abstract}

RESUMO: Foi estudada a reatividade tuberculínica e a resposta imunológica celular e humoral "in vitro", em 50 doentes de ambos os sexos, de 20 a 80 anos de idade, com tuberculose pulmonar ativa, internados no Parque Hospitalar do Mandaqui da Secretaria de Estado da Saúde, São Paulo (Brasil), no período de maio a agosto de 1980. Para o estudo da reatividade tuberculínica foi utilizado o PPD, Rt-23, 2 UT, tendo havido 14,0\% de não-reatores, $12,0 \%$ de reatores fracos e $\mathbf{7 4 , 0 \%}$ de reatores fortes. $O$ estudo da imunidade celular e humoral "in vitro" foi realizado pela quantificação de linfócitos $T$ e $B$, transformação blástica de linfócitos, liberação do fator inibidor da migração de leucócitos (LIF) e reação de hemaglutinação passiva. Os resultados mostraram a validade do cálculo do número absoluto dos linfócitos T e B. A cultura de linfócitos e a técnica do LIF, foram capazes de detectar a sensibilização dos linfócitos ao PPD, mesmo nos doentes não reatores, e a reação de hemaglutinação passiva revelou a presença de anticorpos específicos na população estudada em títulos superiores aos encontrados em pessoas normais, independentemente da reatividade tuberculinica.

UNITERMOS: Tuberculose pulmonar. Teste tuberculínico.

\section{INTRODUÇĀO}

Os primeiros trabalhos experimentais monstrando que animais de laboratório sobre a resposta imune do organismo primo-infectados apresentam proteção contra infectado pelo Mycobacterium tuberculosis novas inoculações do bacilo, sendo essa foram feitos por Robert Koch em 1891, de- reação conhecida como fenômeno de Koch.

Realizado no Departamento de Epidemiologia da Faculdade de Saúde Pública da USP Av. Dr, Arnaldo, 715 - 01255 - São Pallo, SP - Brasil e na Seção de Imunologia do Instítuto Adolfo Lutz - Av. Dr. Arnaldo, 355 - 01246 - São Paulo, SP - Brasil.

* Da Seção de Imunologia do Instituto Adolfo Lutz - São Paulo, SP - Brasil.

*** Da Escola de Enfermagem da USP - Av. Dr. Enéas Carvalho de Aguiar, $419-05403-$ São Paulo, SP - Brasil

** Do Departamento de Epidemiologia da Faculdade de Saúde Pública da USP - São Paulo, $\mathrm{SP}$ - Brasil. 
Paralelamente a esse estudo, Robert Koch obteve a tuberculina bruta, de triturados bacilares, substância que julgou pudesse ser utilizada no tratamento da doença. Embora - seu valor terapêutico não tenha sido confirmado, ficou evidente a possibilidade de sua utilização para o diagnóstico da infecção, indicativa da presença do bacilo no organismo do hospedeiro, independentemente de ser ou não doente.

Os trabalhos de Von Pirquet, em 1908, permitiram evidenciar que animais de laboratório inoculados com proteinas estranhas ou certos microorganismos apresentam reações diferentes quando inoculados novamente com o mesmo antígeno.

Com o desenvolvimento dos recursos operacionais, a aplicação do teste tuberculínico por escarificação cutânea de Von Pirquet, utilizando a tuberculina bruta de Koch em diferentes diluições, possibilitou os primeiros estudos, em larga escala, sobre o levantamertto da hipersensibilidade tuberculínica em diferentes países.

Já na década de 50 , a utilização de um derivado protéico purificado do $M$. tuberculosis (PPD, Rt-23), aplicado segundo a técnica de Mantoux, possibilitou a homogeinização e a quantificação do teste tuberculínico. A mesma substância é aplicada em doses quantificadas, em diferentes regiões, permitindo a comparação de dados e o estudo da variação das respostas cutâneas para a mesma dose do antígeno empregado.

Contudo, as reaçós de hipersensibilidade e de imunidade, presentes no fenomeno de Koch e nos trabalhos iniciais de Von Pirquet, não ficaram claramente definidas durante muito tempo. A opinião geral era de que os dois fenômenos seriam causados por mecanismos diferentes, relacionados à presença de bacilos vivos no organismo.

Estudando a relação entre esses fenômenos, Rich :t (1946) mostrou não haver diminuição da imunidade quando realiza a dessensibilização tuberculinica de orga- nismos infectados, utilizando doses crescentes da própria tuberculina diluida, a ponto de não haver reação cutânea quando aplicada em dose normal.

Mais recentemente, Mackaness ${ }^{14}$ (1968) defendeu a hipótese de que a hipersensibilidade tuberculínica seria a manifestação da imunidade. Esta hipótese é baseada na observação de que os dois fenômenos coexistem no animal após a vacinação com BCG, que nos animais vacinados há uma relação entre o grau de hipersensibilidade e o de imunidade, que ambos os fenômenos são reativados pela revacinação e ambos podem ser transferidos, de um animal para outro, pelá transfusão de linfócitos esplênicos, mas não pela de soro de animais racinados.

Em relação a tuberculose humana, encontram-se doentes com lesões graves e hipersensibilidade tuberculínica baixa ou ausente, e outros, com lesões discretas e hipersensibilidade elevada. Idêntica variação de resposta ao teste tuberculínico observa-se na tuberculose-infecção. Em ambas as situações a hipersensibilidade tuberculinica pode revelar variações da resposta imune (i) licspedeiro, com lesões específicas em fases diferentes de evolução, à presença de antígeno.

Os estudos de Youmans e Youmans $3 \overline{5}, 36$ (1969) vieram mostrar que embora resultantes da presença de bacilos viáveis no organismo do hospedeiro, os dois fenômenos se manifestam como respostas independentes, dadas por frações diferentes do próprio bacilo. A fração imunogênica, isolada do conteúdo ribossômico intracelular, do bacilo, é de natureza lábil e capaz de desenvolver imunidade sem hipersensibilidade. Outra fração, isolada da membrana celular, é fracamente inunogênica e fortemente hipersensibilizante. $O$ conteúdo da membrana celular contém ainda, o fator corda, agente responsável pela reação granulomatosa, evidenciada quando micobactérias viáveis ou uma suspensāo contendo membrana celular são injetadas no animal de experimentação. 
ARAUJO, A.C. de et al. Reatividade tuberculínica e resposta imunológica celular e humoral "in vitro" em doentes com tuberculose pulmonar. Rev. Saúde públ., S. Paulo, 17:94-111,1983.

Este problema não é de interesse apenas teórico, mas também prático. Uma das maiores objeções para a vacinação indiscriminada com BCG intradérmico, é a de que ela não produz apenas proteção contra a tuberculose, mas desenvolve concomitantemente a hipersensibilidade tuberculínica, dificultando a utilização do teste de Mantoux para o diagnóstico da infecção específica.

O desenvolvimento dos conhecimentos científicos e o aprimoramento das técnicas de laforatório nos últimos anos, tem possibilitado a realização de pesquisas em novas áreas de experimentação, visando detectar "in vitro" as peculiaridades da resposta imune do hospedeiro à presença do agente infeccioso.

Por ser o bacilo de Koch um parasita intracelular facultativo e a infecção por ele causada estar intimamente associada à hipersensibilidade tardia, a tuberculose é considerada como protótipo de doença de imuniciade mediada por células, no homem.

Os linfócitos $\mathrm{T}$ (timo dependentes), céluias imunologicamente competentes que em sua interação com o antígeno transformam-se em células blásticas pironinofílicas, produzem substâncias de baixo peso molecular, as linfocinas, ativas sobre os macrófagos, agentes inespecíficos da imunidade.

Contudo, o conceito de imunidade na tuberculose envolve também a presença de linfócitos B (timo independentes), que dão origem aos plasmócitos (células formadoras de anticorpos), responsáveis pela imunidade humoral.

Esses dois tipos de resposta imune, celular e humoral, podem existir simultaneamente na tuberculose. Embora a imunidade mediada por células esteja presente na maioria dos fenômenos de interação bacilo-hospedeiro, a imunidade humoral também participa de maneira menos ativa.

No presente trabalho foram pesquisadas as respostas imunes, celular e humoral "in vitro", e a reatividade tuberculínica ao PPD, Rt-23, 2UT, em doentes com tuberculose pulmonar ativa visando oferecer subsidios para o conhecimento da evolução da tuberculose no homem.

\section{MATERIAL E METODOS}

No periodo de maio a agosto de 1980 foram feitos estudos da reatividade tuberculinica e da resposta imunológica celular e humoral "in vitro", em 50 doentes com tuberculose pulmonar bacilifera, idades de 20 a 80 anos, sendo 11 do sexo feminino e 39 do sexo masculino, internados no Parque Hospitalar do Mandaqui da Secretaria de Estado da Saúde de São Paulo.

A reatividade tuberculínica foj realizada pelo teste de pele de hipersensibilidade tardia com PPD, Rt-23, 2 UT, segundo técnica padronizada pela Organização Mundial de Saúde, feito anteriormente à colheita de sangue paraos testes imunológicos. Foram considerados reatores fortes os que apresentaram 10 e mais $\mathrm{mm}$ de enduração, reatores fracos de 5 a $9 \mathrm{~mm}$ e não reatores os que tiveram até $4 \mathrm{~mm}$ de enduração.

De cada doente foram retirados $30 \mathrm{ml}$ de sangue venoso: $25 \mathrm{ml}$ com adição de 10 unidades de heparina/ml e $5 \mathrm{ml}$ sem anticoagulante. $O$ sangue heparinizado foi utilizado para a contagem de leucócitos totais, contagem específica de leucócitos, contagem de linfócitos $\mathrm{T}$ e $\mathrm{B}$, transformação blástica dos linfócitos e pesquisa do fator inibidor da migração de leucócitos (LIF). Do sangue sem anticoagulante foi utilizado - soro para a pesquisa de anticorpos pela reação de hemaglutinação passiva (HAP). Serviram de controle, 50 pessoas normais, adultos doadores do Banco de Sangue no Hospital das Clínicas da Faculdade de Medicina da USP, que foram avaliados quanto ao número de leucócitos totais, contagem especifica de leucócitos e contagem de linfócitos $T$ e $B$.

Outro grupo, compreendendo 300 pessoas normais, estudantes, idades variando entre 14 e 20 anos, serviram como controle na padronização da técnica HAP.

A contagem de leucócitos totais foi feita em hemocitômetro e o resultado expresso em 
ARAUJO, A.C. de et al. Reatividade tuberculinic a e resposta imunologica celular e humoral "in vitro" em doentes com tuberculose pulmonar. Rev. Saúde públ., S. Paulo, 17:94-111,1983.

leucócitos por $\mathrm{mm}^{3}$ de sangue e a contagem específica feita pelo esfregaço corado com Leishman. Segundo o grupo controle foram considerados normais os valores compreendidos entre 4.500 e 8.400 leucócitos por $\mathrm{mm}^{3}$ e 950 e 2.300 linfócitos por $\mathrm{mm}^{3} \mathrm{de}$ sangue.

Para a contagem de linfócitos $T$ e $B$ foi usada a técnica da roseta conjunta E-Zy-C' baseada nas descrições de Kajdacsy-Balla e Mendes 11 (1976) e Campbell e col.6 (1974) com algumas adaptaçōes para as condiçōes do laboratório. A separação dos linfócitos foi feita segundo o método descrito por Böyum * (1968) usando sangue heparinizado submetido a gradiente de ciensidade com Ficoll - Hypaque, densidade 1.076. A nuvem de mononucleares obtida foi lavada em solução salina tamponada de Hanks e ajustada a uma concentração de $3.10^{\circ}$ células por $\mathrm{ml}$ e a eles adicionados: a) hemácias de carneiro; b) complexo ativado zymosan-complemento, usando zymosan produzido no Laboratório de Imunologia do Instituto Adolfo Lutz segundo Pillemer e col.22 (1956) e soro de camundongo como fonte de complemento. A leitura foi feita após incubação por $18 \mathrm{~h}$ a $4^{\circ} \mathrm{C}$, pela contagem de 100 células e considerando linfócitos $\mathrm{T}$ aqueles que apresentaram 3 ou mais hemácias de carneiro aderidas à sua superfície, e linfócitos $B$ aqueles que apresentaram 3 ou mais partículas de zymosan aderidas. Os valores finais, expressos em percentagem, foram resultantes da média de três contagens de cada preparação. Os valores absolutos de linfócitos $T$ e $B$ foram obtidos em função do número de leucócitos totais e número absoluto de linfócitos de cada uma das pessoas estudadas.

Foram considerados valores normais para linfócitos $\mathrm{T}$ aqueles compreendidos entre 52 e $76 \%$ e 500 e 1.400 linfócitos por $\mathrm{mm}^{3}$ e para linfócitos $\mathrm{B}$ os compreendidos entre 10 e $18 \%$ e 85 e 346 por $\mathrm{mm}^{3}$ de sangue.

Para o estudo da transformação blástica dos linfócitos, foram obtidos linfócitos por separação em gradiente de densidade de
Ficoll-Hypaque e acertados para uma concentração de $1.10^{\circ}$ células por $\mathrm{ml}$ de meio TC 199 suplementado com $10 \%$ de soro $\mathrm{AB}$ humano, inativado a $56^{\circ} \mathrm{C}$ por $30 \mathrm{~min}$. As células foram cultivadas em duplicatas, com ou sem adição de $100 \mu \mathrm{g} / \mathrm{ml}$ de PPD, por 8 dias a $37^{\circ} \mathrm{C}$ em atmosfera de $5 \%$ de $\mathrm{CO}_{2}$. Após $72 \mathrm{~h}$ de incubação, foi adicionada $3 \mathrm{H}$-Thymidine numa concentração final de $1 \mu \mathrm{C} / \mathrm{ml}$ de meio. No oitavo dia, a reação foi interrompida pela centrifugação e posterior adição de ácido tricloroacético a $5 \%$, por $18 \mathrm{~h}$ a $4^{\circ} \mathrm{C}$. Após nova centrifugação, o residuo marcado foi lavado em metanol, seco em estufa $37^{\circ} \mathrm{C}$ e solubilizado em protosol por $2 \mathrm{~h}$ a $45^{\circ} \mathrm{C}$. Os tubos com material marcado e solubilizado foram lavados com a adição de $10 \mathrm{ml}$ de líquido de cintilação e o conteúdo transferido para frascos de contagem de um espectrofotometro de cintilação líquida.

A relação de transformação dos linfócitos (RTL) foi calculada pelas contagens por minuto (cpm), na presença e ausência de antigeno (Ag).

$$
\mathrm{RTL}=\frac{\mathrm{cpm} \text { da cultura na presença do } \mathrm{Ag}}{\mathrm{cpm} \text { da cultura na ausência do } \mathrm{Ag}}
$$

Foram considerados que os pacientes apresentam linfócitos sensibilizados ao PPD, quando estes, em cultura, respondem transformando-se em células pironinofílicas, incorporando ${ }^{3} \mathrm{H}$-Thymidine em seus DNA e dando RTL maior que 1,5 .

O fator inibidor da migração dos leucócitos (LIF), descoberto por Rocklin ${ }^{26}$ (1974) foi pesquisado pela técnica descrita por Rosemberg e David 27 (1970), adaptada para as condições do laboratório.

As células utilizadas para essa técnica foram obtidas de plasma rico em leucócitos totais, e que após lavagens em solução salina tamponada de Hanks foram ressuspensas em meio TC 199 suplementado com $10 \%$ de soro fetal bovino numa concentração de $10^{7}$ células $/ \mathrm{ml}$ e aspiradas em tubos capilares de polietileno. Os capilares cheios foram fechados e centrifugados para separação 
ARAUJO, A.C. de et al. Reatividade tuberculínica e resposta imunológica celular e humoral "in vitro" em doentes com tuberculose pulmonar. Rev. Saúde públ., S. Paulo, 17:94-111,1983.

dos leucócitos e colocados em câmaras de migração cheias de meio TC 199 mais $10 \%$ de soro fetal bovino, contendo ou não PPD na concentração de $25 \mu \mathrm{g} / \mathrm{ml}$, que foram incubadas a $37^{\circ} \mathrm{C}$ em câmara úmida durante $18 \mathrm{~h}$. Para o material de cada doente foram montadas 4 câmaras de migração: 2 contendo o antígeno e 2 sem o antígeno. A leitura da área de migração dos leucócitos foi feita com auxílio de planímetro, e os resultados expressos em Indice de Migração (IM), resultante da relação:

$I M=\frac{\text { área de migração na presença do } \mathrm{Ag}}{\text { área de migração na ausência do } \mathrm{Ag}}$

Onde o IM foi maior ou jgual a 0,9 , segundo o "WHO Handbook of Immunological Techniques" 34 , foi considerado que houve liberação da linfocina LIF.

A pesquisa de anticorpos, pela reação de HAP padrão descrito por Boyden ${ }^{3}$ (1951), foi feita com hemácias de carneiro taninizadas e sensibilizadas com $20 \mu \mathrm{g}$ de antigeno protéico extraido de vacina $B C G$ oral, segundo Espinosa e col.8 (1978). Os soros testes foram diluidos na razão dois e o título de anticorpos expresso pela maior diluição do soro que dá reação positiva definida. Paralelamente foram corridos controles de soros positivos e negativos e controle de hemácias não sensibilizadas.

\section{RESULTADOS E COMENTARIOS}

A Tabela 1 mostra o resultado do teste tuberculínico segundo a idade, a qual variou de 20 a 80 anos, onde 7 ou $14,0 \%$ foram năo reatores, 6 ou $12,0 \%$ reatores fracos e 37 ou $74,0 \%$ reatores fortes, com um total de 43 ou $86,0 \%$ de reatores.

A maoir percentagem das pessoas $(80,0 \%)$ encontrava-se nos grupos etários entre 20 a 49 anos. Para os reatores fortes e total de reatores, houve uma diminuição das percentagens da reatividade tuberculinica com $o$ aumento da jdade. A existência de 7 doentes não reatores mostra que $14,0 \%$ de pessoas com tuberculose pulmonar não responderam ao teste cutâneo de sensibilidade tuberculínica. Tarantino e col.32 (1975) afirmam que cerca de 5,0\% dos doentes com tuberculose pulmonar ativa apresentam resultado negativo as teste tuberculínico, usando PPD, Rt-23, 2 UT. Mc Murray e Echeverri 18 (1978) e Nash e Douglas 20 (1980) encontraram 25,0\% de não reatores ao PPD em doentes com tuberculose pulmonar ativa, à dose de 5 UT de PPD, enquanto Mc Murray 17 (1980) verificou também que quando foi utilizada a dose de 250 UT de PPD, essa percentagem de $25,0 \%$ diminuiu para $10,0 \%$. Como no presente estudo o teste tuberculínico não foi repetido nem foram usadas doses maiores de PPD ou uma bateria de testes cutâneos de rotina para pesquisa da capacidade reacional do organismo (candidina, histoplasmina, varidase, sensibilização ao dinitroclorobenzeno) como fizeram Chaparas e col.5 (1970), Malaviya e col.16 (1975), Mc Murray ${ }^{17,18}$ (1978 e 1980) e Nash e Douglas 20 (1980), não foi possível constatar se a negatividade do teste foi devida a causas técnicas de aplicação do antigeno, dose insuficiente de PPD, incapacidade de reação por deficiência imunológica, por doença em fase adiantada ou por idade avançada.

A Tabela 2 e Fig. 1(A) mostram a reatividade tuberculínica segundo o número de leucócitos, onde 31 ou $62,0 \%$ dos doentes apresentaram número aumentado, 3 ou $6,0 \%$ número diminuído e 16 ou $32,0 \%$ número normal. A leucocitose encontrada em $62,0 \%$ dos doentes é condizente com processo infeccioso.

Quanto ao número de linfócitos (Tabela 3, Fig. 1(B), 29 ou $58,0 \%$ dos doentes estão na faixa de normalidade e 21 ou $42,0 \%$ estão com valores aumentados.

Houve relação inversa entre reatividade tuberculínica e número de linfócitos, onde as percentagens de reatores são menores nos doentes com linfocitose.

Smith e Reichman ${ }^{30}$ (1972) afirmam que a falta de reatividade tuberculínica observada em doentes com tuberculose ativa 

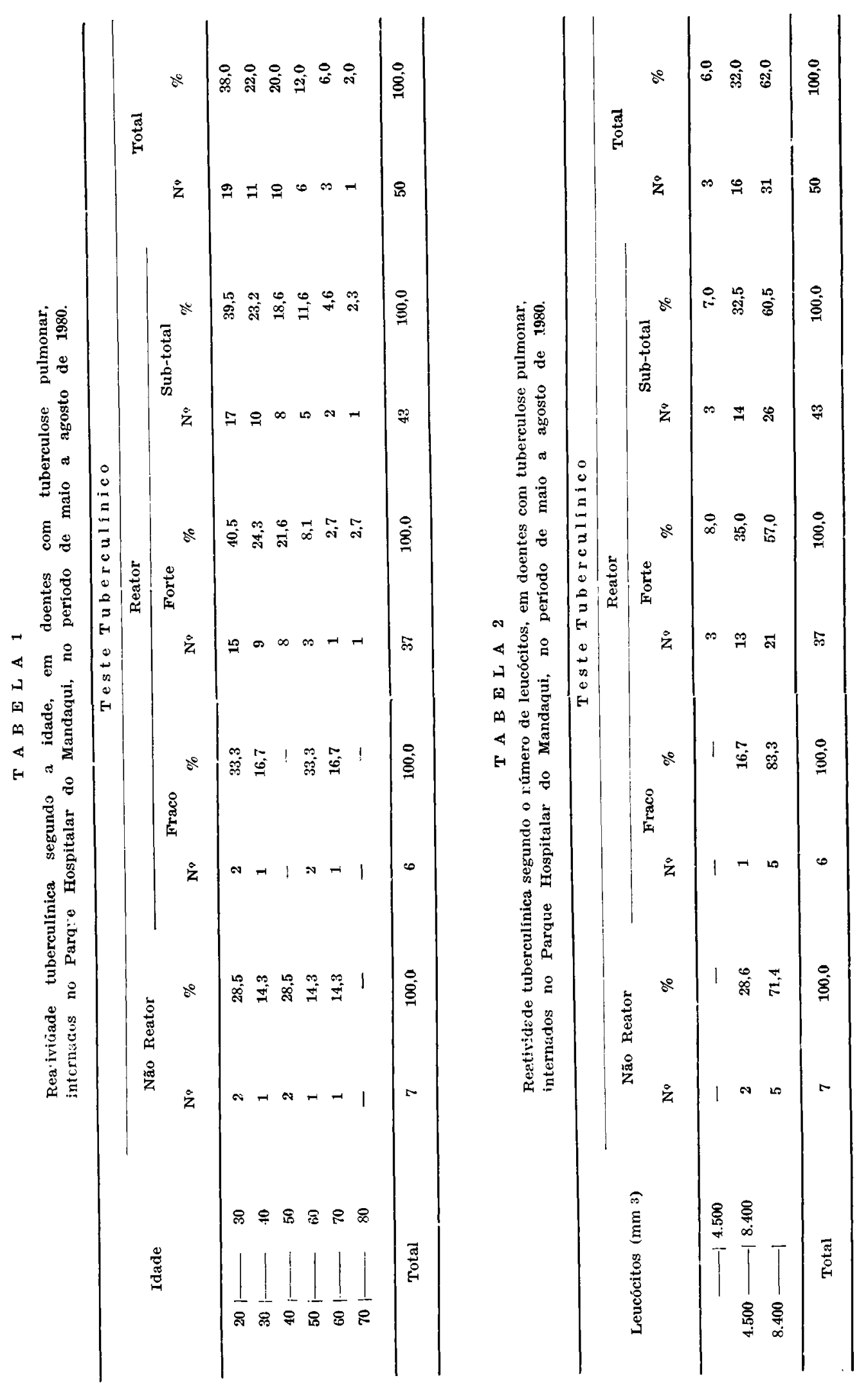
ARAtJo, A.C. de et al. Reatividade tuberculínica e resposta imunológica celular e humoral "in vitro" em doentes com tuberculose pulmonar. Rev. Saúde públ., S. Paulo, 17:94-111,1983.

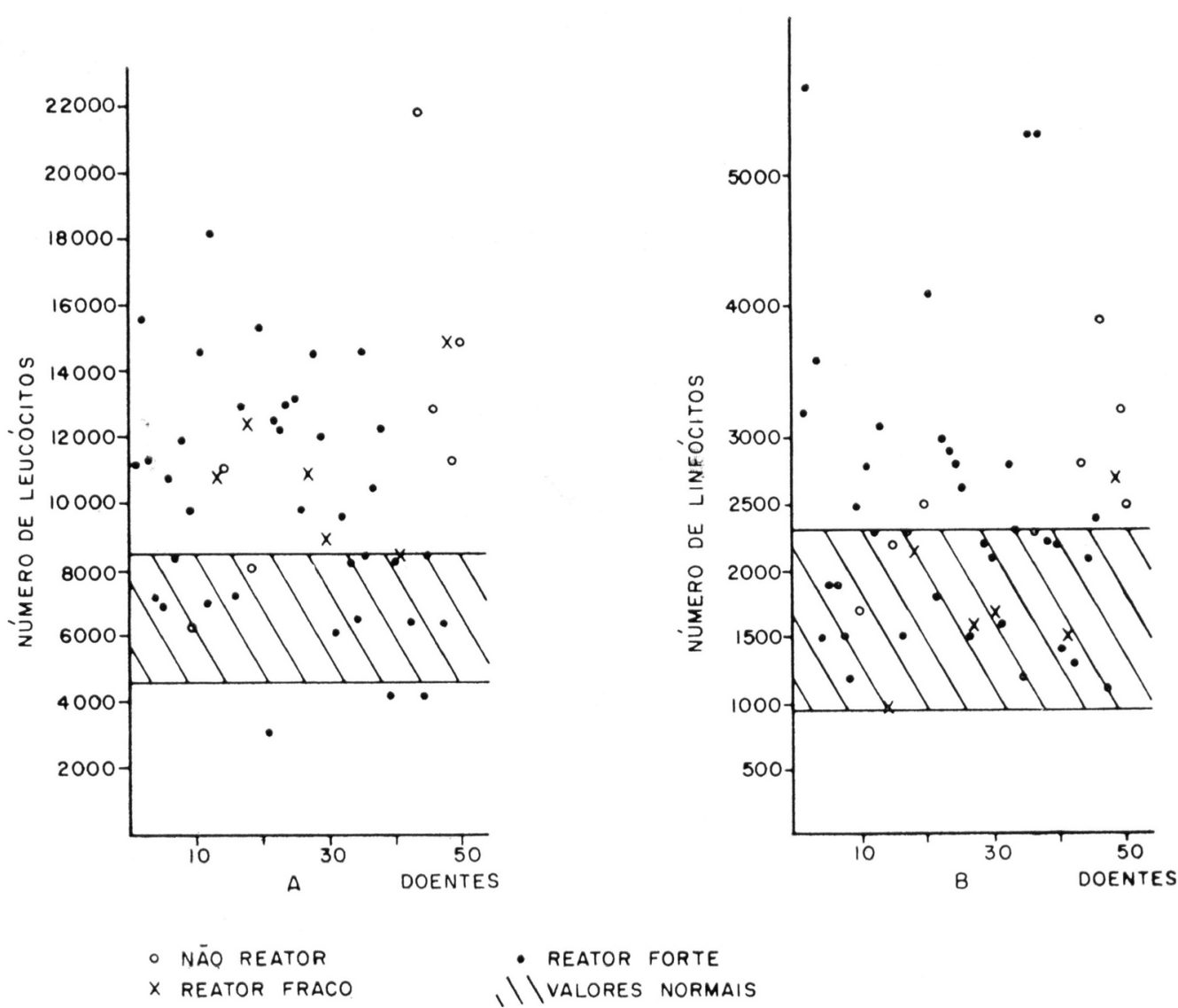

Fig. 1 - Distribuição dos resultados do teste tuberculínico e do número de leucócitos (A) e lintócitos (B) por $\mathrm{mm}$ s de sangue, em doentes com tuberculose pulmonar.

poderia ser explicada por uma linfocitopenia, 0 que não foi observado neste trabalho onde os 7 doentes que não reagiram ao $P P D$ tiveram número de linfócitos normal ou aumentado.

A Tabela 4 e Fig. 2(A) mostram a reatividade tuberculínica segundo as percentagens de linfócitos $T$. No total, 36 ou $72,0 \%$ dos doentes apresentaram valores normais, 3 ou $6,0 \%$ valores diminuidos e 11 ou 22,0 valores aumentados. Relacionando reatividade tuberculínica com percentagem de linfócitos $\mathrm{T}$, houve maiores percentagens de reatores na faixa de normalidade de linfócitos $T$.
A Tabela 5 e Fig. 2(B) mostram a relação da reatividade tuberculinica e o número de linfócitos $T$, onde no total 26 ou $52,0 \%$ dos doentes apresentaram valores normais e 24 ou $48,0 \%$ valores aumentados, não havendo nenhum doente com número diminuido. Esses resultados mostram a importância de se trabalhar com número absoluto de linfócitos, o qual demonstra a população real de linfócitos $T$ no sangue circulante.

A relação entre a reatividade tuberculinica e o número de linfócitos $T$ foi semeThante à da Tabela 4 para numeros normais e aumentados de linfócitos $T$, onde houve maiores percentagens de reatores con 

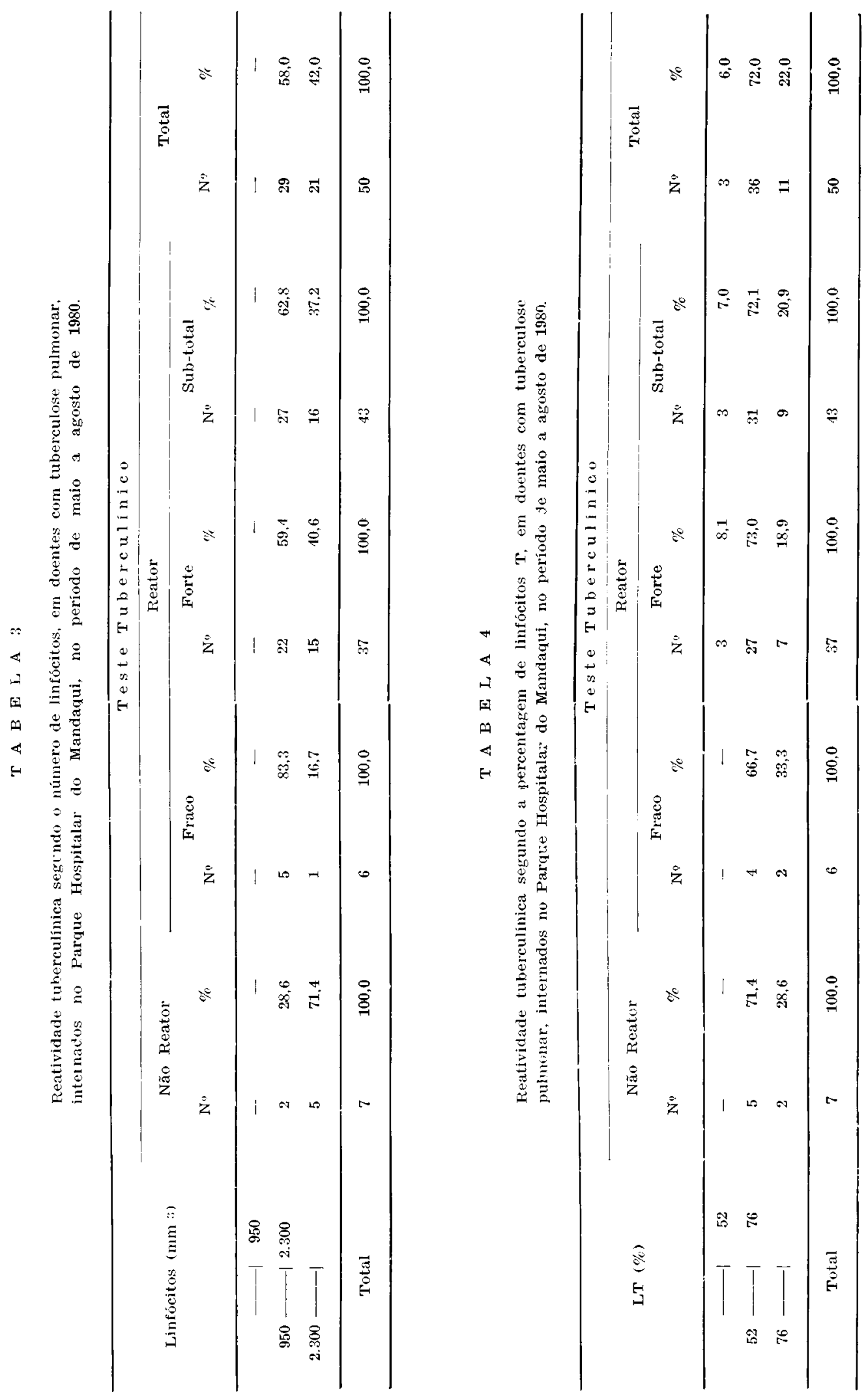
ARAUJO. A.C. de et al. Reatividade tuberculínica e resposta imunológica celular e humoral "in vitro" em doentes com tuberculose pulmonar. Rev. Saúde públ., S. Paulo, 17:94-111.1983.
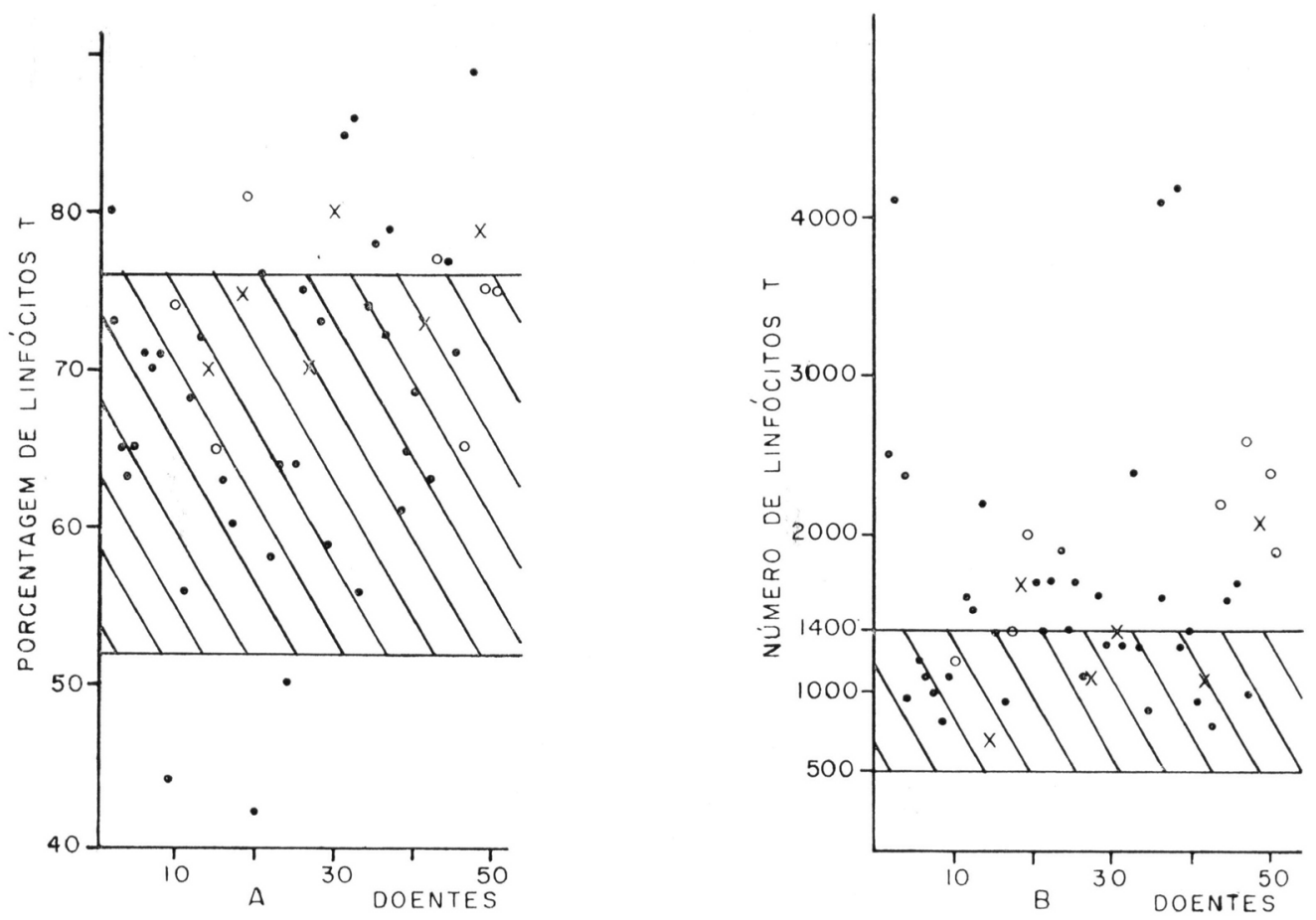

Fig. 2 - Distribuição dos resultados do teste tuberculinico e número de linfócitos $\mathrm{T}$ en percentagem (A) e valor absoluto (B). em doentes com tuberculose pulmonar.

número normal de linfócitos $T$ do que con número aumentado.

Os resultados encontrado: são discordantes dos de Al-Tawil e Thewaini 1 (1978), Bhatnagar e col."- (1977), Magarāo ${ }^{1.5}$ (1977) e Skvor e Trnka (1979), que encontraram número de linfócitos $T$ diminuidos em doentes com tuberculose pulmonar ativa, enquanto Kventy 1:2 (1977) encontrou valores aumentados de linfócitos $T$ em pessoas com tuberculose avançada, yuando comparados com grupos controles, constituidos por pessoas não tuberculosas.

Essa divergencia de resultados pode estar associada ao fato de ter sido utilizado, no presente estudo, alguns doentes já em trata- mento, com 3 a 4 semanas de internação e, portanto, já com possivel melhora da resposta celular. $O$ número de linfócitos $T$ circulantes pode estar aumentado para intensificar resposta imune, uma vez que ela está deprimida no inicio da doença e atinge valores normais com o tratamento e posterior cura, como afirmam Malaviya e col. ${ }^{\text {ti }}$ (1975), Mc Murray 1- (1980) e Zeitz e cols: (1974).

A Tabela 6 e Fig. 3 mostram que 30 ou $60,0 \%$ dos doentes apresentaram percentagem de linfócitos B diminuida (menor que $10 \%$ ) sendo que o major número de pessoas pertencem ao grupo de reatores fortes. Entretanto, a análise dos valores absolutos (Tabela 7 e Fig. 3) revela que apenas 4 

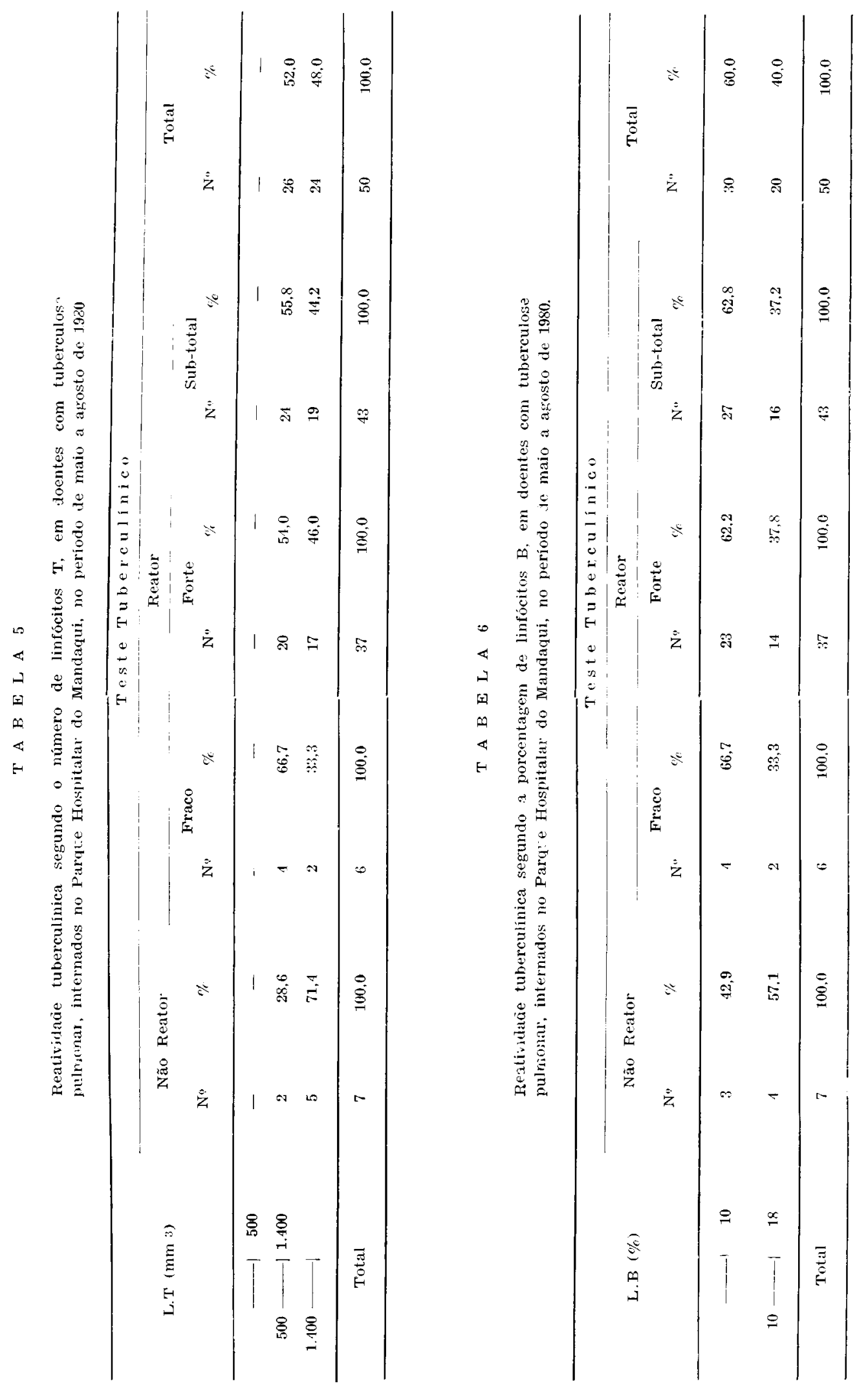


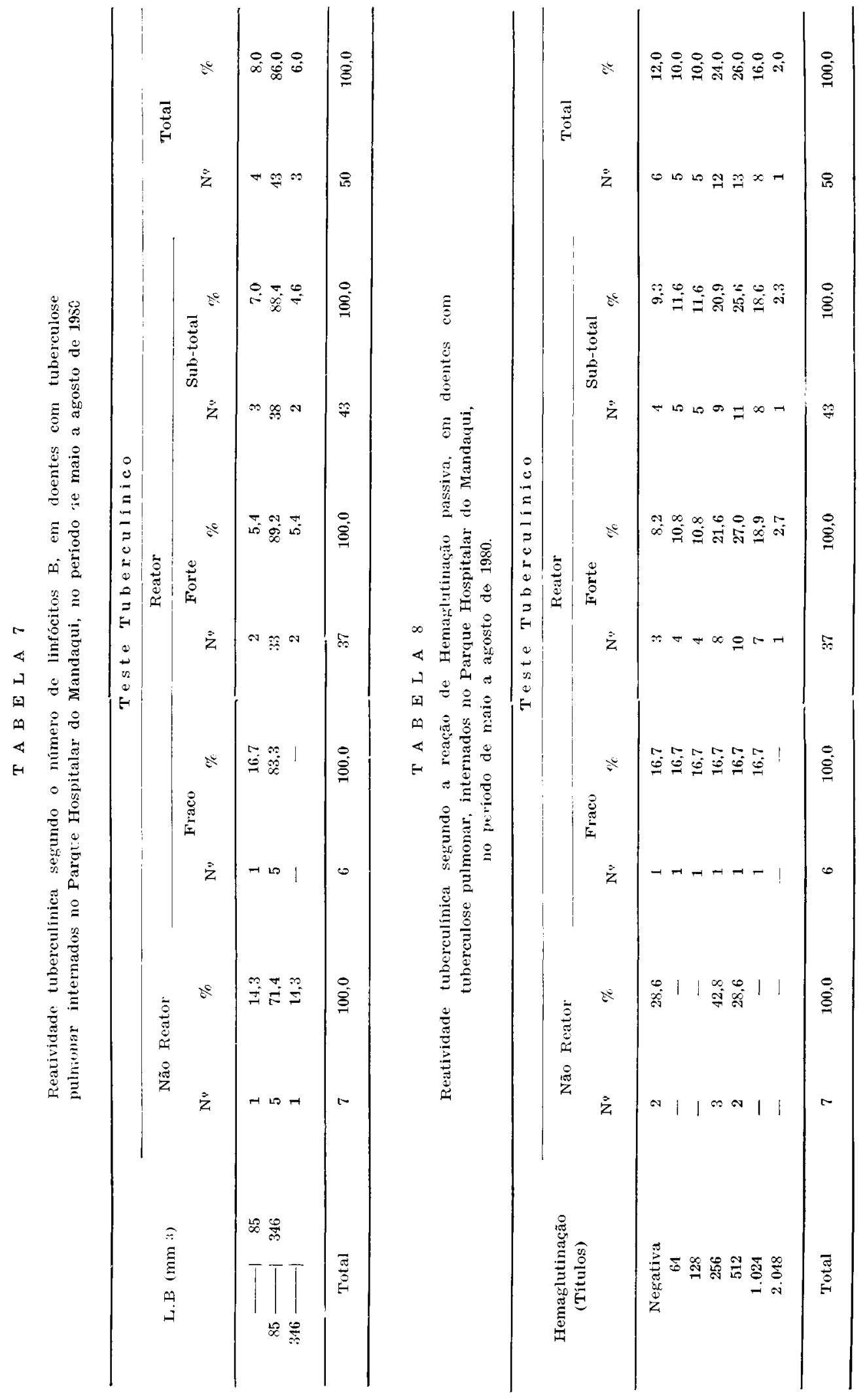


ARAUJO. A.C. de et al. Reatividade tuberculínica e resposta imunológica celular e humoral "in vitro" em doentes com tuberculose pulmonar. Rev. Saúde públ., S. Paulo, 17:94-111,1983.
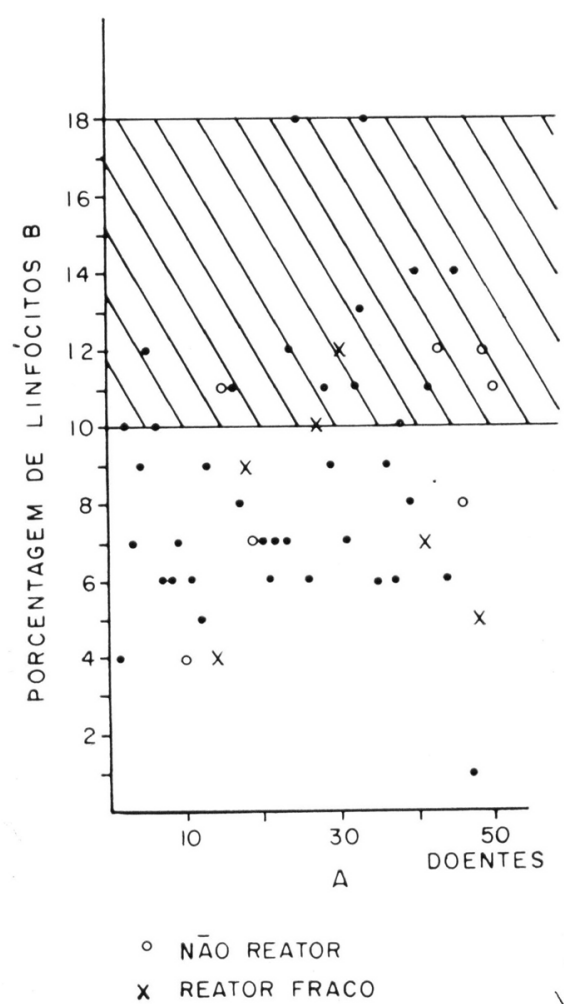

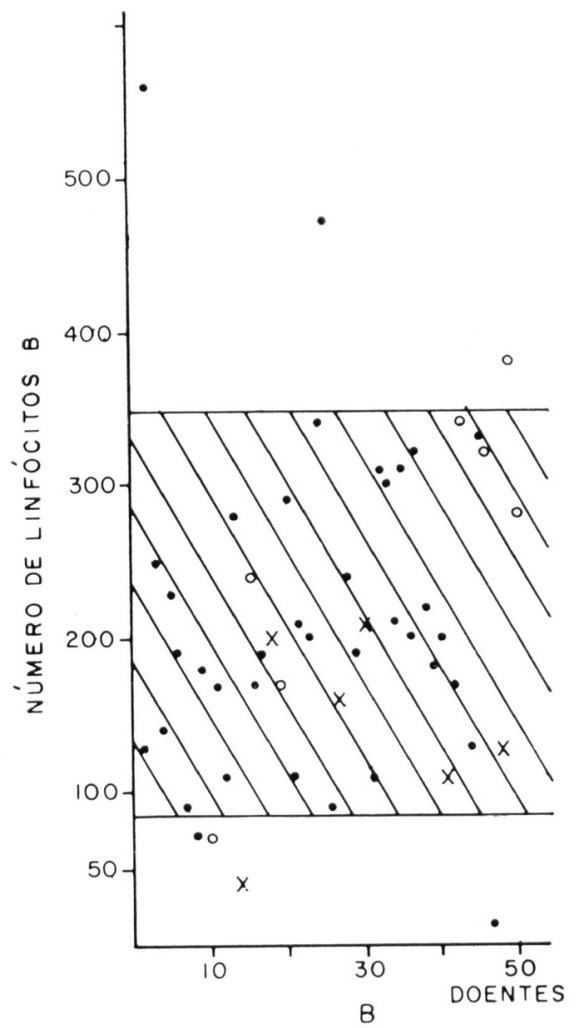

- reator forte

VALORES NORMAIS

Fig. 3 - Distribuição dos resultados do teste tuberculínico e número de linfócitos $B$ em percentagem (A) e valor absoluto (B), em doentes com tuberculose pulmonar.

ou $8,0 \%$ das pessoas apresentaram valores diminuidos, 43 ou $86,0 \%$ valores normais e 3 ou $6,0 \%$ valores aumentados, confirmando a importância de se avaliar número absoluto de linfócitos $\mathrm{T}$ e $\mathrm{B}$.

Esses dados contradizem as observaçōes de Al-Tawil e Thewaini ${ }^{1}$ (1978), Bhatnagar e col.2 (1977) e Magarão 15 (1977) que encontraram apenas valores normais de linfócitos $B$ em pessoas com tuberculose pulmonar ativa.

Al-Tawil e Thewaini 1 (1978), além de avaliar o número de linfócitos $\mathrm{B}$, estudaram seu estado funcional pela aplicação de vacina tifóide, a fim de estimular essas células e induzir a formação de anticorpos. Os resultados obtidos indicam que a função dos linfócitos B também não estava alterada.

A resposta humoral, avaliada pela reação de hemaglutinação passiva (Tabela 8), mostra que 6 ou $12,0 \%$ dos doentes apresentaram resultados negativos e 44 ou $88,0 \%$ mostraram positividade, com maior incidência de títulos de 256, 512 e 1024 e com predominância de reatores fortes. A maioria das pessoas apresentou altos títulos de anticorpos, significando que seus linfócitos B estavam funcionantes. 

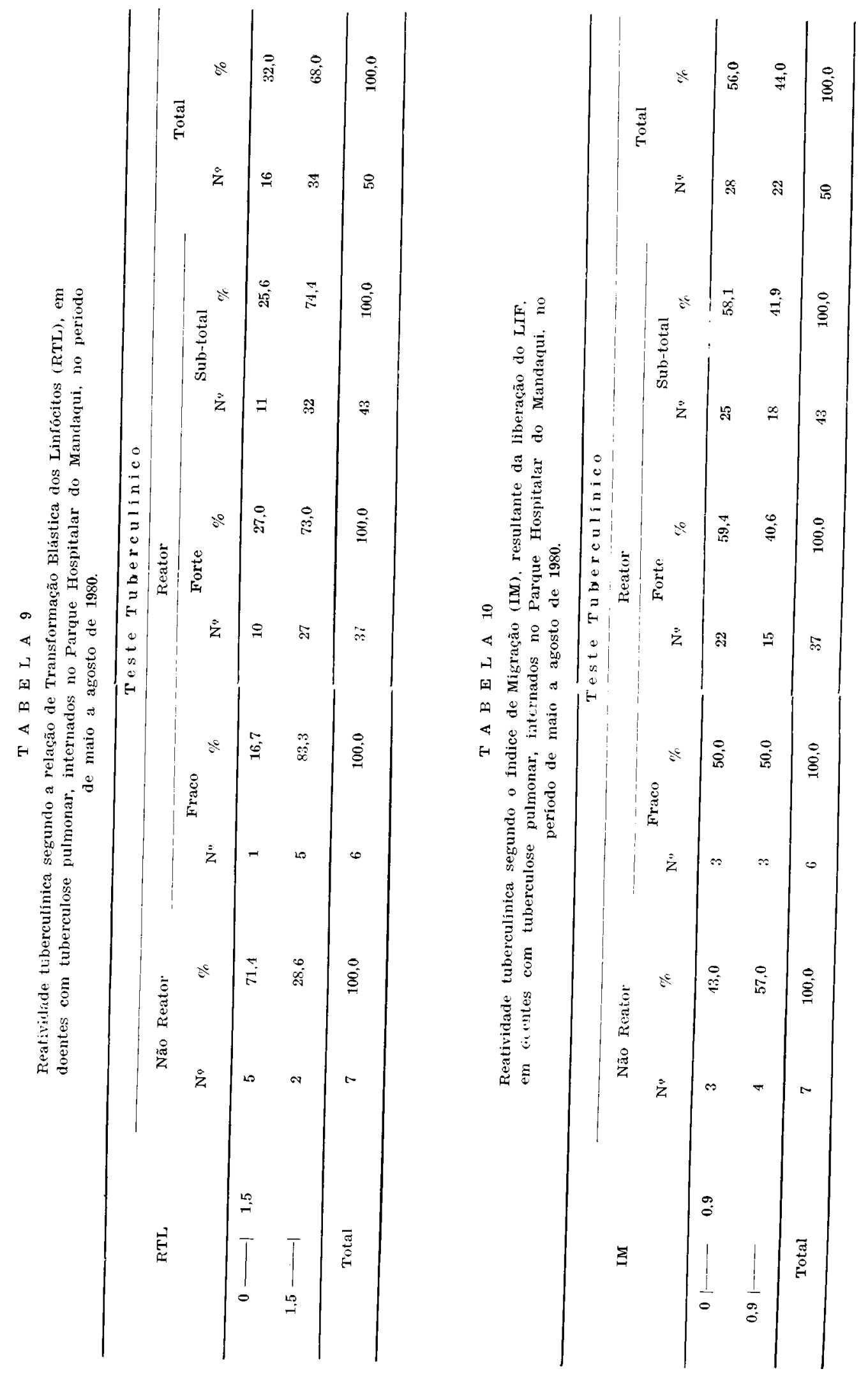


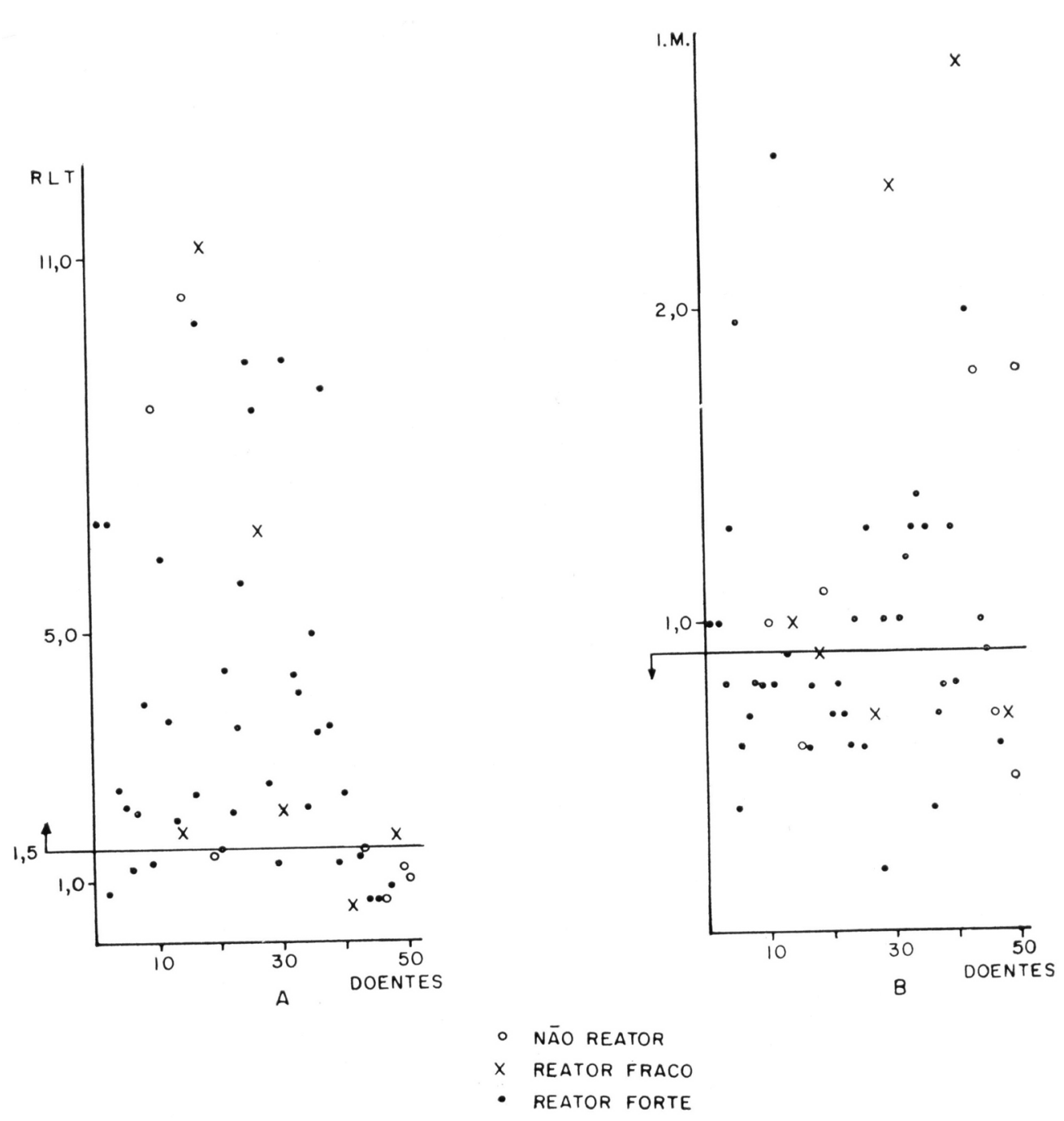

Fig. 4 - Distribuição dos resultados do teste tuberculínico, da transformação blástíca dos linfócitos (A) e do LIF (B), em doentes com tuberculose pulmonar.

Quando foram testados soros de pessoas normais, vacinadas ou não com BCG intradérmico, por essa técnica, foi verificado que os mesmos não apresentavam anticorpos ou os apresentavam em títulos não significativos, levando a crer que é necessária a doença e não apenas o contacto com o bacilo para a produção de anticorpos em altos títulos.
Grange e col. ${ }^{9}$ (1980) e Tandon e col. ${ }^{31}$ (1980), utilizando a técnica de ELISA (Enzyme Linked Immunosorbent Assay), detectaram anticorpos contra antígenos micobacterianos em 75 a $80 \%$ e $79,4 \%$ respectivamente, em doentes com tuberculose. A alta percentagem de positividade obtida, no presente trabalho, pela reação de hemaglutinação $(88,0 \%)$, assegura sua validade 
ARAUJO, A.C. de et al. Reatividade tuberculínica e resposta imunológica celular e humoral "in vitro" em doentes com tuberculose pulmonar. Rev. Saúde públ., S. Paulo, 17:94-111,1983.

como um dado complementar em casos suspeitos de tuberculose.

A Tabela 9 e Fig. 4 mostram a transformação blástica dos linfócitos em resposta ao PPD, onde 16 ou $32,0 \%$ dos doentes não apresentaram resposta e 34 ou $68,0 \%$ apresentaram resposta com índices acima de 1,5 . Dos 7 doentes não reatores, 5 ou $71,4 \%$ não responderam na cultura e 2 ou $28,6 \%$ responderam com índices dos mais altos $(10,4$ e 6,8), conforme mostra a Fig. 4. Dos 37 doentes reatores fortes, 10 ou $27,0 \%$ não apresentaram resposta e 27 ou $73,0 \%$ responderam com indices significativos de transformação. Entre os reatores fracos, um não apresentou resposta e 5 ou $83,3 \%$ a apresentaram.

A presença de 10 ou $27,0 \%$ de reatores fortes, cujos linfócitos não entraram em transformação blástica, poderia ser explicada pela presença de fatores ou células supressoras na cultura, ou então, pela dose de PPD utilizada de $10 \mu \mathrm{g} / \mathrm{ml}$ de meio de cultura, talvez insuficiente para induzir resposta dos linfócitos, já que Ellner e col. ${ }^{7}$ (1979) chegaram a utilizar doses de $100 \mu \mathrm{g}$ de PPD $/ \mathrm{ml}$ de meio.

Por outro lado, a técnica mostrou-se sensivel na detecção de resposta dos linfócitos em cultura na presença de antígeno específico, em 2 doentes não reatores e em 5 reatores fracos. Resultados semelhantes foram encontrados por Jensen e col $^{10}$ (1977), Miller e Jones 19 (1973), Repo e col.2:3 (1980), Sarkany e Hales 28 (1968) e Smith e Reichman ${ }^{30}$ (1972).

Segundo Miller e Jones ${ }^{19}$ (1973) existe uma relação linear entre a dose minima de tuberculina requerida para detectar sensibilidade pelo teste de pele e o logarítmo do índice de transformação dos linfócitos, sugerindo que pequenas reaçōes de pele de um a $4 \mathrm{~mm}$, embora consideradas não reativas pelos critérios epidemiológicos estabelecidos, são eventos imunológicos importantes.

Quanto à transformação blástica positiva em doentes não reatores no teste tuberculi- nico, Jensen e col. ${ }^{10}$ (1977) encontraram um PPD 19 s no soro o que, segundo eles, seria o responsável pelo bloqueio da reação "in vitro"; entretanto, nas pessoas com transformação blástica e reatores no teste tuberculínico, esse PPD, livre ou formando complexo, não foi encontrado e sim um anticorpo anti PPD, detectado por hemaglutinação passiva.

A Tabela 10 e Fig. 5 mostram a inibição da migração dos leucócitos (LIF), onde 28 ou $56,0 \%$ dos doentes apresentaram liberação dessa linfocina e 22 ou $44,0 \%$ não a mostraram. Dos 7 doentes não reatores, 3 ou $43,0 \%$ a liberaram; entre os reatores fracos não houve divergência de resultados; entre os reatores fortes, 22 ou $59,4 \%$ liberaram a linfocina e no total de reatores houve igualmente maior percentagem $(58,1 \%)$ de doentes que a liberaram.

Lockshin ${ }^{13}$ (1969) e Rieger e col.25 (1979) tentaram correlacionar o LIF com teste tuberculínico, mas sem sucesso. Isso pode ser explicado pelo fato de que por está técnica mede-se uma linfocina que age mais sobre polimorfonucleares, enquanto no teste tuberculínico há maior envolvimento de mononucleares e, portanto, correlação com o teste de inibição da migração de macrófagos (MIF).

A pesquisa do LIF tem sido correlacionada com melhora clínica e redução de bactérias no doente. Trnka e Skvor ${ }^{33}$ (1979), avaliando a liberação do LIF e a presença de bactérias no escarro de doentes com tuberculose, durante 12 semanas de terapia conseguiram correlacionar o desaparecimento da bactéria com aumento dos IM, isto é, diminuição da liberação do LIF.

E provável que os doentes que apresentaram IM maior do que 0,9 estivessem respondendo melhor ao tratamento, sob o impacto de menor número de bactérias em relação aos que tiveram IM menores.

Nikolov 21 (1978) demonstrou que a progressão do processo infeccioso é acomparhada pela inibição da transformação blás- 
ARAUJO, A.C. de et al. Reatividade tuberculínica e resposta imunológica celular e humoral "in vitro" em doentes com tuberculose pulmonar. Rev. Saúde públ., S. Paulo, 17:94-111,1983.

tica dos linfócitos e aumento da liberação do LIF.

$O$ fato de 3 dos 7 doentes não reatores nāo responderem na cultura de linfócitos e liberarem o LIF poderia estar associado com mau prognóstico. Se isso for provado, o LIF seria importante como subsidio para o prognóstico do tratamento e de eventuais recidivas.

\section{CONCLUSOEES}

Os resultados obtidos no presente trabalho, mostram as seguintes conclusões:

1. A hipersensibilidade tuberculinica as PPD, Rt-23, 2 UT, pesquisada em 50 doentes com tuberculose pulmonar ativa, revelou $14,0 \%$ de não reatores, $12,0 \%$ de reatores fracos e $74,0 \%$ de reatores fortes.

2. Para a população de estudo, conı idades variando de 20 a 80 anos, houve declínio das percentagens de reatores fortes e totais de reatores com o aumento da idade.

3. Houve leucocitose em $62,0 \%$ dos doentes, independentemente da reatividade cutânea ao teste tuberculínico.

4. Houve linfocitose em $71,4 \%$ dos doentes não reatores e valores normais de linfócitos em $62,8 \%$ dos totais de reatores.

5. Para percentagens de linfócitos $T$, houve valores normais em $71,4 \%$ de não reatores e em $72,1 \%$ dos totais de reatores.
6. Para os valores absolutos de linfócitos $T$ houve aumento do número dos mesmos em $71,4 \%$ dos não reatores e em $44,2 \%$ dos totais de reatores.

7. Para percentagens de linfócitos $B$ houve valores diminuídos dos mesmos em $42,9 \%$ dos não reatores e em $62,8 \%$ dos totais de reatores.

8. Para valores absolutos de linfócitos $B$ houve normalidade em $71,4 \%$ dos não reatores e em $88,4 \%$ dos totais de reatores, e diminuição dos mesmos em $14,3 \%$ dos não reatores e em $7,0 \%$ do total de reatores.

9. Os anticorpos para antígenos protéicos extraidos de vacina $B C G$ oral estiveram presentes em $88,0 \%$ da população de análise, com títulos elevados $(\geqslant 256)$ em $71,4 \%$ dos não reatores e em $67,4 \%$ dos totais de reatores.

10. Houve transformação blástica de linfócitos, utilizando o PPD, Rt-23, como antígeno, em $28,6 \%$ dos não reatores e em $74,4 \%$ do total de reatores.

11. Houve liberação do fator inibidor da migração de leucócitos (LIF) utilizando o PPD, Rt-23, como antigeno, em $43,0 \%$ dos não reatores e em $58,1 \%$ do total de reatores.

\section{AGRADECIMENTOS}

Ao Dr. Auad Atalla, Diretor do Parque Hospitalar do Mandaqui e às enfermeiras Maria Camargo e Marila Magno Ferreira, pela colaboração na execução do teste tuberculínico da população de análise. 
ARAUJO, A.C. de et al. Reatividade tuberculínica e resposta imunológica celular e humoral "in vitro" em doentes com tuberculose pulmonar. Rev. Saúde públ., S. Paulo, 17:94-111,1983.

ARAUJO, A. C. de et al. [Delayed-type skin reaction to tuberculin and the cellular and humoral immune response "in vitro" in patients with pulmonary tuberculosis]. Rev. Saúde públ., S. Paulo, 17:94-111, 1983.

ABSTRACT: This paper presents the results of delayed-type skin reaction to tuberculin and the cellular and humoral immune responses "in vitro" in 50 patients with active pulmonary tuberculosis admitted to the "Parque Hospitalar do Mandaqui", São Paulo, Brazil, in the period from May to August 1980, matched for sex and ranging in age from 20 to 80 years old. In order to study the delayed-type skin reaction to tuberculin, the PPD, Rt-23, 2 TU (Purified protein derivative) was used and the result obtained was of $14.0 \%$ of nonreactors, $12.0 \%$ of weak reactors and $74.0 \%$ of strong reactors. The "in vitro" study of cellular and humoral immune responses was carried out by determining the number of $T$ and $B$ lymphocytes, the lymphocyte transformation, the liberation of the leucocyte inhibitor factor (LIF) and by the passive hemaglutination test. The results showed the importance of calculation of the absolute number of $T$ and $B$ lymphocytes. The culture of lymphocytes and the LIF experiment were able to detect the lymphocyte sensitivity to PPD even in the nonreactor patients and the passive hemaglutination test showed the presence of specific antibodies in the population studied demonstrated by the highest titers when compared with normal subjects, independently of the skin reactivity to tuberculin.

UNITERMS: Tuberculosis, pulmonary. Tuberculin test.

\section{REFERENCIAS BIBLIOGRĀFICAS}

1. AL-TAWIL, N.G. \& THEWAINI, A.J. Stuay of the immunological status of pulmonary tuberculosis. Scand. J. Immunol., $8: 333-8,1978$.

2. BHATNAGAR, R.; MALAVIYA, A.N.; NARAYANAN, S.: RAJGOPALAN, P.: KUMAR, R. \& BHARADWAJ, O.P. Spectrim of immune response abnormalities in different clinical forms of tuberculosis. Amer, Rev. resp. Dis., 115:207-12, 1977.

3. BOYDEN, S.V. The absorption of proteins on erythrocytes treated with tannic acid and subsequent haemagglutination by antiprotein sera. J. exp. Med. 93:107-20, 1951.

4. BOYUM, A. Separation of leukocytes from blood and bone marrow: introd:ction. Scand. J. clin. Invest., 21 (suppl. 97): 7, 1968.

5. ChaPARAS, S.D.; SHEAGREN, J.N.; DE. MEO, A. \& HEDRICK, $S$. Correlation of human skin reactivity with lymphocyte transformation induced by mycobacterial antigens and histoplasmin. Amer, Rev, resp. Dis., 101:67-73, 1970.
6. CAMPELL, A.R.; WALLER, C; WOOD, J.; AYNSLEY GREEN, A \& YU, V. Lymphocyte subpopulation in blood of newborn infants. Clin. exp. Immunol., $18: 469-82,1974$

7. ELLNER, J.J.; SCHACTER, B.Z. \& BHE F.T. Tuberculin response of lymphocytes from himan skin test nonreactors. Evidence for in vitro primary sensitization of $\mathbf{T}$ lymphocytes. Cell. Immunol., $45: 213-20,1979$

8. ESPINOSA, O.R.; PASCUAL, F.Q.; ANAYA, N. \& PARRO, S.E. Antimycobacterial antibodies in tuberculosis. Rev. Invest. clin., $30: 121-6,1978$.

9. GRANGE, J.M.; GIBSON, J. \& BATTY, A. The specificity of the humoral immune response to soluble mycobacterial antigens in tuberculosis. Tubercle, 61:153-6, 1980.

10. JENSEN, B.; KURPISZ, M. \& RUBIN, B. Antigen specific lymphocyte activity in vitro by perypheral blood leucocytes from Mantoux positive and negative human beings. I. Comparison of quantitative differences in the PPD specific lymphoproliferative response of lymphocytes from the two kinds of donors. Clin. exp Immunol., 27:303-12, 1977. 
ARAUJO, A.C. de et al. Reatividade tuberculínica e resposta imunológica celular e humoral "In vitro" em doentes com tuberculose pulmonar. Rev. Saude públ., S. Paulo, 17:94-111,1983.

11. KAJDACSY-BALLA, A.A. \& MENDES, N.F. Rosette formation between human $B$ lymphocytes and zymosan- $\mathrm{C}^{\prime}$, complexes using different complement sources. J. Immunol. Meth., 9:205-9, 1976.

12. KVENTY, J. $T$ lymphocyte determination in tuberculosis. Scand. J. resp. Dis., $58: 181-4,1977$.

13. LOCKSHIN, M.D. Failure to demonstrate leucocyte migration. Inhibition in human tuberculin hypersensitivity. Proc. Soc. exp. Biol. Med., 132:928-30, 1969.

14. MACKANESS, G.B. The immunology of antituberculous immunity. Amer. Rev. resp. Dis., $97: 337-44,1967$.

15. MAGARAO, M.F. Imlnidade celular e humoral na tuberculose pulmonar ativa. Rev. Inst. Med. trop. S. Paulo. 19:1-9. 1977.

16. MALAVIYA. A.N.; SEHGAL, K.L.; KUMAR, R. \& DINGLEY, H.B. Dinitrochlorobenzene contact sensitization in pulmonary tuberculosis. Clin. exp. Immunol., 22 :339-403. 1975.

17. McMURRAY, D.N. Mechanisms of anergy in tuberculosis. Chest, 77:4-5, 1980.

18. McMURRAY, D.N. \& ECHEVERRI, A. Cell mediated immunity in anergic patients with pulmonary tuberculosis. Amer. Rev. resp. Dis., 118:827-34, 1978.

19. MILLER, S.D. \& JONES, H.E. Correlation of lymphocyte transformation with tuberculin skin test sensitivity. Amer. Rev. resp. Dis., 107:530-7, 1973.

20. NASH, D.R. \& DOUGLASS, J.E. Anergy in active pulmonary tuberculosis. A comparison between positive and negative reactors and an evaluation of $5 \mathrm{TU}$ and $250 \mathrm{TU}$ skin test doses. Chest, 77:32-6, 1980.

21. NIKOLOV, G.D. Changes in cell mediated immune reactions dependent on the form and development of pulmonary tuberculosis. Frolia med., 20(2): 15.91978.

22. PILLEMER, L.; BLUM, L.; LEPOW, I.H. : WURZ, L. \& TODD, E. The properdin system and immunity. III - The zymosan assay of properdin. J. exp. Med., 103:1-13, 1950.

23. P.EPO, H.; KOSTIALA, A.A.I. \& KOSUNEN, T.U. Cellular hyperscnsitivity to tuberculin in BCG-revaccinated persons studied by skin reativity, leukocyte migration inhibition and lymphocyte proliferation. Clin. exp. Immunol., $39: 442-8,1980$.

24. RICH, A.R. Patogenia de la tuberculose. Buenos Aires, wdit. Alfa, 1946.
25. RIEGER, M. ; TRNKA, L. \& SKVOR, J. Immunoprofile studies in patients with pulmonary tuberculosis. IV -- Tuberculin reaction and test of inlibition of blood le: kocyte migration. scand. $J$. resp. Dis., 60:355-7, 1979.

26. ROCKLIN, R.E. Products of activated lymphocytes: letkocyte inhibitory factor (LIF) distinct from migration inhibitory factor (MIF). J. Immunol., 112:1461-6, 1974.

27. ROSEMBERG, S.A. \& DAVID, J.R. InhIbition of leucocyte migration: an evaluation of this in vitro assay of delayed hypersensitivity in man to a soluble antigen. J. Immunol., 105:1447-51, 1970.

28. SARKANY, I. \& HALES, H. Lymphocyte transformation following $B C G$ vaccination. Brit. J. Derm., 80:29-34, 1968.

29. SKVOR, J. \& TRNKA, L. Immunoprofile studies in patients with pulmonary tuberculosis. I - Correlation of pretherapy cellular tests with characteristics of the disease. Scand, J. resp. Dis., 60:161-7, 1979.

30. SMITH, J.A. \& REICHMAN, L.B. An aid in the diagnosis of tuberculosis in patients with non-reactive skin test. Amer. Rev. resp. Dis. 106:194-201, 1972.

31. TANDON, A.: SARENA, R.P. \& SAXENA. K.C. Diagnosis potencialites of enzyme-linked immunosorbent assay in tuberculosis using purified tuberculin antigen. Tubercle, 61:87-9, 1980.

32. TARANTINO, A.B. et al. Tuberculose. In: Tarantino, A.B., ed. Doengas pulmonares. Rio de Janeiro, Guanabara-Koogan, 1975. p. 329-98.

33. TRNKA, I. \& SKVOR, J. Direct migration inhibition test with leukocytes as indicador of mycobacterial antigens in the human body. Tubercle, 60:49-54, 1979.

34. WORLD HEALTH ORGANIZATION. Handbook of immunological techniques. Geneva, 1979.

35. YOUMANS, G.P. \& YOUMANS, A.S. Recent studies on acquires immunity in tuberculosis. Curr. Top. Microbiol. Immunol., 48:129-78, 1969.

36. YOUMANS, G.P. \& YOUMANS, A.S. Allergenicity of mycobacterial ribosomal and ribonucleic acid preparations in mice and guinea pigs. J. Bact., 97:134-9, 1969.

37. ZEITZ, S.J.; OSTROW, J.H. \& ARSDEL, P.P.V. Humoral and cellular immunity in the anergic tuberculosis patient. $J$. Allergy clin. Immunol., 53:20-6, 1974.

Recebido para publicagão em 21/08/1982

Aprovado para publicacão em 09/01/198s 